\title{
Doğu Karadeniz Bölgesi Meteorolojik Parametrelerinin Trend Analizi
}

\author{
Cavit Berkay Yilmaz ${ }^{1}$, Vahdettin Demir ${ }^{2}$, Mehmet Faik Sevimli ${ }^{3}$ \\ ${ }^{1}$ KTO Karatay Üniversitesi, Mühendislik Fakültesi, İnşaat Mühendisliği Bölümü, Konya, Türkiye (ORCID: 0000-0002-2734-2073), cavitberkayyilmaz@gmail.com \\ $2^{2 *}$ KTO Karatay Üniversitesi, Mühendislik Fakültesi, İnşaat Mühendisliği Bölümü, Konya, Türkiye (ORCID: 0000-0002-6590-5658), vahdettin.demir@karatay.edu.tr \\ ${ }^{3}$ KTO Karatay Üniversitesi, Mühendislik Fakültesi, İnşaat Mühendisliği Bölümü, Konya, Türkiye (ORCID: 0000-0002-4676-8782), \\ mehmet.faik.sevimli@karatay.edu.tr
}

(2nd International Conference on Access to Recent Advances in Engineering and Digitalization (ARACONF)-10-12 March 2021)

(DOI: 10.31590 /ejosat.916018)

ATIF/REFERENCE: Yılmaz, C., Demir, V. \& Sevimli, M. F. (2021). Doğu Karadeniz Bölgesi Meteorolojik Parametrelerinin Trend Analizi. Avrupa Bilim ve Teknoloji Dergisi, (24), 489-496.

$\ddot{O} \mathbf{z}$

Doğu Karadeniz Bölgesi Türkiye'nin en çok yağış alan bölgesidir. Bu nedenle sıcaklık, yağış gibi meteorolojik parametrelerdeki değişimler bölgedeki hayatı büyük ölçüde etkilemektedir. Bu değişimlerin aşırı yağışların etkisi ile taşkın veya giderek artan sıcaklıkların etkisiyle ortaya çıkan kuraklık gibi insan hayatını ve bölgedeki üretimi etkileyerek sıcaklık ve yağış değişkenleri üzerinde meydana gelen değişikliklerin önemini gözler önüne sermektedir. Bu değişiklikleri tespit etmek amacıyla birçok parametrik ve parametrik olmayan yöntem geliştirilmiştir, bu yöntemlerin başında trend analizleri gelmektedir. Bu çalışmada Meteoroloji Genel Müdürlügü'ne ait Giresun, Trabzon, Rize, Artvin, Gümüşhane, Bayburt illerinde bulunan 6 istasyondan elde edilen 1960-2016 yılları arasını kapsayan 57 yıllık sıcaklık, buharlaşma, rüzgâr ve yağış verileri üzerinde \%95 güven aralığında gerçekleştirilen trend analizlerinde parametrik bir yöntem olan Lineer Trend yöntemi ve parametrik olmayan Modifiye Mann-Kendall yöntemi kullanılmıştır. Bu çalışmanın sonucunda Lineer Trend yöntemi ve Modifiye Mann-Kendall yönteminden elde edilen sonuçların \%86.1-97.22 oranında uyuştuğu saptanmıştır. Sonuçlar olarak incelendiğinde sıcaklık ve yağışların artan yönde eğilim gösterdiği, rüzgarların Trabzon istasyonunda artan, Rize ve Bayburt istasyonlarında azalan yönde anlamlı eğilimler gösterdiği tespit edilmiştir. Buharlaşma verileri ise Bayburt istasyonunda azalan, Gümüşhane ve Trabzon istasyonlarında artan bir eğilim göstermektedir.

Anahtar Kelimeler: Lineer Trend, Modifiye Mann-Kendall, Sıcaklık, Yağış, Rüzgâr.

\section{Trend Analysis of Meteorological Parameters of Eastern Black Sea Region}

\begin{abstract}
The Eastern Black Sea region is the rainiest region of Turkey. Therefore, changes in temperature, precipitation, etc., affect life in the region to a great extent. These changes show the importance of changes in temperature and precipitation variables by affecting human life and production in the region, such as flood caused by excessive precipitation or droughts caused by global warming. In order to detect these changes, many parametric and non-parametric methods have been developed. In this study trend analyzes were applied on 57 (1960-2016) years temperature, winds, evaporation and precipitation data of 6 stations in Giresun, Trabzon, Rize, Artvin, Gümüşhane, Bayburt provinces belonging to Turkish State Meteorological Service. Study was performed in $95 \%$ confidence interval. As a result of this study, the results obtained from Linear Trend method and Modified Mann-Kendall method were found to be 86.197.22 \% concordant. When the results of the Eastern Black Sea Region are examined, it is observed that temperature and precipitation are showed in increasing direction, winds showed significant tendencies in the direction of increasing in Trabzon station and decreasing in Rize and Bayburt stations. Evaporation data showed decreasing trend in Bayburt station and increasing trend in Gümüşhane and Trabzon stations.
\end{abstract}

Keywords: Linear Trend, Modified Mann-Kendall, Precipitation, Temperature, Winds.

\footnotetext{
* Sorumlu Yazar: vahdettin.demir@,karatay.edu.tr
} 


\section{Giriş}

Karadeniz bölgesinin Türkiye'nin en çok yağış alan bölgesi olması sebebiyle meteorolojik parametrelerin bölgeye etkisi göz ardı edilemeyecek kadar fazladır. Bu etki sıcaklıkların artmasıyla kuraklık şeklinde ortaya çıkabileceği gibi aşırı yağışlar ile taşkın sel vb. şekillerde ortaya çıkarak insan hayatını ve bölgenin ekonomisini tehdit edebilmektedir. Bu yüzden sıcaklık, yağış gibi hidrolojik parametrelerin incelenmesi, geleceğe yönelik eğilimlerinin araştırılması çok önemlidir. Yeryüzü şekilleri, toprak ve bitki örtüsünün oluşumu ile insan faaliyetleri üzerinde iklim faktörünün oldukça belirleyici ve sınırlandırıcı etkileri bulunmaktadır. Bu nedenle, iklim elemanlarında zaman içerisinde meydana gelen değişim ve eğilimlerin belirlenmesi, değişim ve eğilimin yönü ve boyutunun tespit edilmesi son derece önemlidir. İklimde zaman içerisinde meydana gelen olumlu ve olumsuz yöndeki değişim ve eğilimlerin ortaya konulması, ekstrem koşullara rastlanılması durumunda alınması gereken tedbirlerin erkenden fark edilmesini kolaylaştırmaktadır (Yılmaz, 2018). Çeribaşı ve Doğan (2015) Batı Karadeniz, Doğu Karadeniz ve Sakarya havzalarının yıllık ortalama yağış miktarlarına ait veriler üzerinde trend analiz yöntemlerini uygulayarak elde etmiş olduğu sonuçlarda Batı Karadeniz Havzası'nda artan veya azalan yönde bir trend varlığına rastlamamış, Doğu Karadeniz Havzası'nda ise artan yönde, Sakarya havzasında ise azalan yönde trend varlığ gözlemlemiştir. Çeribaşı (2019) Doğu Karadeniz havzasında bulunan 9 istasyona ait yağış verilerine periyodu 1971-2000 yılları arası olmak üzere uygulamış olduğu trend testleri sonucunda Rize, Ünye ve Pazar istasyonlarında \%90 güven aralığında artan yönde trend varlığına rastlarken geriye kalan 6 istasyonda trend varlığına rastlamamıştır. Partal (2003) Türkiye genelinde incelediği 96 istasyonda yapmış olduğu çalışma içerisinde yağış verilerinin incelenmesi sonucu kış mevsimi incelendiğinde Orta ve Doğu Karadeniz Bölgesi'nde azalma trendi varlığını saptamıştır. Yılmaz (2018) yapmış olduğu tez çalışmasında Karadeniz Bölgesi'ndeki 16 istasyona uygulamış olduğu Mann-Kendall ve Spearmann Rho trend test yöntemlerinden elde ettiği sonuçlar incelendiğinde Batı Karadeniz'de sıcaklık değerlerinde artan yönde trend varlığına rastlamıştır. Özkoca (2015) Orta Karadeniz'in kıyı şeritlerinde yapmış olduğu çalışmada sıcaklık açısından bölge genelinde artan yönde trend varlığına ve bölgedeki yağışlar açısından ise iç kesimlerdeki istasyonların denize yakın istasyonlara göre azalan yönde trend varlığı gösterdiği sonucuna ulaşmıştır. Nemli (2017) Doğu Karadeniz Bölgesi'ne ait 10 adet meteoroloji istasyonu üzerinde yürütmüş olduğu çalışmasında standart zamanlarda maksimum yağış yüksekliklerini incelemiş ve bölge genelinde artan trend varlığını saptamıştır. Demir (2018) yapmış olduğu tez çalışmasında Karadeniz Bölgesi yağışlarının trend analizini gerçekleştirerek, Doğu ve Orta Karadeniz Bölgesi'nde artan trend, Batı Karadeniz Bölgesi'nde ise azalan trend tespit etmiştir.

\section{Materyal ve Metot}

\subsection{Veri çalıșma alanı}

$\mathrm{Bu}$ çalışmada, Şekil 1'de gösterilen istasyonlara ait, Meteoroloji Genel Müdürlüğü'nden temin edilen, 1960-2016 (57 yıl) yıllarını kapsayan aylık toplam yağış, ortalama sıcaklık, ortalama rüzgâr hızı ve buharlaşma verileri kullanılmıştır. Tablo 1 de istasyonlara ait bilgiler yer almaktadır.

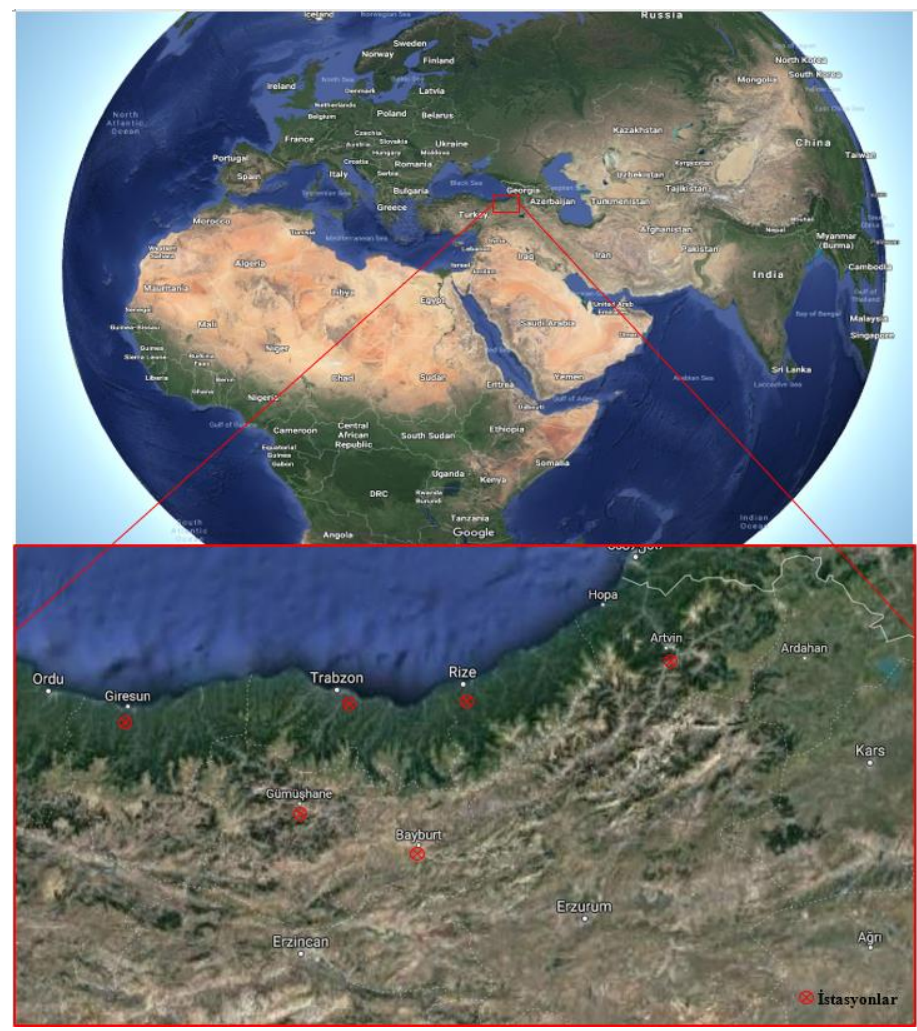

Şekil 1. Çalışmada kullanılan Doğu Karadeniz Bölgesi'nde bulunan istasyonlar

Tablo 1. Istasyonlara Ait Konum Bilgileri

\begin{tabular}{ccccc}
\hline $\begin{array}{c}\text { İstasyon } \\
\text { No }\end{array}$ & $\begin{array}{c}\text { İstasyon } \\
\text { Adı }\end{array}$ & $\begin{array}{c}\text { Enlem } \\
\left.\mathbf{(}^{\circ}\right)\end{array}$ & $\begin{array}{c}\text { Boylam } \\
\left.\mathbf{(}^{\circ}\right)\end{array}$ & $\begin{array}{c}\text { Rakım } \\
(\mathbf{m})\end{array}$ \\
\hline 17034 & Giresun & 40.92 & 38.39 & 37 \\
17037 & Trabzon & 41 & 39.78 & 39 \\
17040 & Rize & 41.04 & 40.5 & 9 \\
17045 & Artvin & 41.18 & 41.82 & 628 \\
17088 & Gümüşhane & 40.46 & 39.47 & 1219 \\
17089 & Bayburt & 40.25 & 40.43 & 1584 \\
\hline
\end{tabular}

\subsection{Yöntemler}

\subsubsection{Lineer trend yöntemi $(L T)$}

LT yöntemi temelinde Regresyon analizine dayanır ve verilerin normal dağılıma uyduğunu varsayan parametrik bir testtir. "x" ve "y" değişkenleri arasındaki ilişkiyi, doğrusal bir trendin var olup olmadığını test eder (Karabulut ve Cosun 2009). $\mathrm{Bu}$ yöntemle elde edilen $\mathrm{yi}=\mathrm{a}+\mathrm{bxi}$ şeklindeki eğrinin " $\mathrm{b}$ " terimi eğimi " $a$ " terimi ise eğrinin Kartezyen koordinat sisteminde " $y$ " eksenini kestiği noktayı gösterir. "a" ve "b" terimleri (Denklem 1 ve 2) aşağıdaki gibi hesaplanır;

$$
\begin{aligned}
& b=\frac{\sum_{i=1}^{n} x_{i} y_{i}-n \bar{x} \bar{y}}{\sum_{i=1}^{n} x_{i}^{2}-n \bar{x}^{2}} \\
& a=\bar{y}-b \bar{x}
\end{aligned}
$$


Trendin olup olmadığ 1 ise $t$ dağılımı ve t testi ile belirlenir. " $t$ " dağılımı normal dağılım gibi simetrik bir dağılımdır. Ortalaması 0'dır. Dağılımın serbestlik derecesi $\mathrm{n}=\mathrm{N}-1$ dir. Burada N veri sayısıdır. Denklem 1 yardımıyla hesaplanan b değerine (eğim) ait $\mathrm{t}$ değeri hesaplanır (thes) ve seçilen bir anlamlılık düzeyi ile karşılaştırılır (bu çalışmada \%95 güven aralığında). Eğer kabul edilen aralığı aşıyorsa gidiş vardır ve işaretine göre artan ya da azalandır. Aşmıyorsa $\left(-\mathrm{t}_{\text {cri }}<\mathrm{t}_{\text {hes }}<\mathrm{t}_{\text {cri }}\right)$ gidiş yoktur denilmektedir (Demir, 2018).

\subsubsection{Modifiye Mann-Kendall yöntemi (M-MK)}

Mann-Kendall (MK) testi için ilk olarak "S" yani MK test istatistiği toplam değeri hesaplanmalıdır. Bu amaçla veri sütunları ilk ölçüm tarihinden son ölçüm tarihine sıralanmalıdır $(i=1, \ldots, n-$ 1 'e kadar sıralanmış $x_{i}$ veri sütunu ile $j=i+1, \ldots$, n'e kadar sıralanmış $x_{j}$ veri sütunlarını oluşturacak şekilde). Ardından, $x_{i}$ veri sütunu başlangıç olarak kullanılır ve diğer sıralanmış $\mathrm{x}_{\mathrm{j}}$ ile Denklem 3'deki signum fonksiyonu kullanılarak Denklem 4'deki belirtilen " $S$ " değeri hesaplanır. Bu işlemler sonucunda tüm veri çiftlerinin farkı $\left(\mathrm{x}_{\mathrm{j}}-\mathrm{x}_{\mathrm{i}}\right)$ ile pozitif ve negatif değerlerin sayısının toplamı bulunmuş olur.

$$
\begin{aligned}
& \operatorname{sgn}\left(x_{j}-x_{i}\right)=\left\{\begin{aligned}
1 ; & \text { Ĕger } x_{j}>x_{i} \\
0 ; & \text { Ĕger } x_{j}=x_{i} \\
-1 ; & \text { Ĕger } x_{j}<x_{i}
\end{aligned}\right. \\
& S=\sum_{i=1}^{n-1} \sum_{j=i+1}^{n} \operatorname{sgn}\left(x_{j}-x_{i}\right)
\end{aligned}
$$

Veri sayısı "n" olmak üzere $n>10$ ise seriler için varyans hesabı yapılır (Denklem 5) ve yaklaşık olarak normal dağılıma uygun olduğu öngörülür. Varyans hesaplandıktan sonra, Denklem 4'de bulunan " $S$ " değerine göre " $Z$ " hesaplanır. Hesaplanan Z değeri de, belirlenen olasılık düzeylerine karşılık gelen normal dağılım çizelgesindeki standart $\mathrm{Z}$ değerleriyle karşılaştırılır (Yu vd., 1993).

$$
\begin{aligned}
& \operatorname{Var}(S)=\frac{n(n-1)(2 n+5)-\sum_{i=1}^{P} t_{i}\left(t_{i}-1\right)\left(2 t_{i}+5\right)}{18} \\
& Z=\left\{\begin{array}{cl}
\frac{S-1}{\sqrt{\operatorname{Var}(S)} ;} & \text { Ĕ̈er } S>0 \\
0 ; & \text { Ĕger } S=0 \\
\frac{S+1}{\sqrt{\operatorname{Var}(S)} ;} & \text { Ĕger } S<0
\end{array}\right.
\end{aligned}
$$

\section{Denklem 5'te;}

$\mathrm{n}$ : veri serisi uzunluğu,

P: serideki bağlı grupların sayıları,

$\mathrm{t}_{\mathrm{i}}$ : i uzunluğundaki bir seride bağlı gözlemlerin sayısını ifade etmektedir.

Trendin olup olmadığı ise Normal dağılımın $Z$ değerleri ile belirlenir. Denklem 6 yardımıyla hesaplanan $\mathrm{Z}$ değeri, $\alpha$ e-ISSN: 2148-2683 anlamlılık düzeyine karşı gelen normal dağılımın $Z_{1-\alpha / 2}$ değerinden büyük olduğu durumlarda sifir hipotezi $\left(\mathrm{H}_{0}\right)$ kabul edilmemektedir. Yani, zaman serisinde bir eğilimin söz konusu olduğu sonucuna varılmaktadır. Benzer şekilde $Z$ değeri, dağılım çizelgesindeki $\mathrm{Z}_{1-\alpha / 2}$ değerinden küçük olduğu durumlarda $\mathrm{H}_{0}$ kabul edilmemektedir ve zaman serisinde istatistiksel olarak anlamlı bir eğilimin olmadığ 1 anlaşılmaktadır. S değeri pozitif hesaplanırsa, incelenen olayda artan yönde, negatif hesaplanırsa azalan yönde bir eğilim olduğu sonucuna varılır (Mann, 1945; Kendall, 1975).

Modifiye Mann-Kendall (M-MK) yöntemi ise test istatistiğinin varyansındaki modifiye değere dayanarak, otokorele edilmiş veriler için uygun olan değiştirilmiş bir parametrik olmayan trend yöntemidir. Modifiye testin ampirik önem seviyesi açısından doğruluğunun, herhangi bir güç kaybı olmadan orijinal Mann-Kendall trend testinden üstün olduğu tespit edilmiştir. MMK testinde ise hesaplanan varyans değerinde oto-korelasyonun etkisi de dikkate alınır. Düzeltilmiş varyans ifadesi aşağıda verildiği gibi hesaplanır ve Denklem 6 yardımıyla $\mathrm{Z}$ değerleri bulunur (Hamed ve Rao, 1998).

$$
\begin{gathered}
V(S)=\operatorname{Var}(S) * \frac{n}{n_{s}^{*}}=\frac{n(n-1)(2 n+5)}{18} * \frac{n}{n_{s}^{*}} \\
\frac{n}{n_{s}^{*}}=1+\frac{2}{n(n-1)(n-2)} \sum_{i=1}^{n-1}(n-i)(n-i-2) \rho_{s}(i)
\end{gathered}
$$

Burada $\mathrm{n} / \mathrm{n}_{\mathrm{s}}{ }^{*}$, verilerdeki oto-korelasyon nedeniyle bir düzeltmeyi temsil eder. " $n$ " gerçek gözlem sayısıdır ve $\rho_{\mathrm{s}}$ (i) gözlem saflarının oto-korelasyonudur.

\section{Uygulama}

Trend bir parametrenin zaman serisi boyunca ölçülen büyüklüklerinde anlamlı bir azalma veya artmanın olması olarak tanımlanmaktadır. Hidrolojik büyüklükler (yağış, buharlaşma, akış, sızma) zaman içerisinde rastgele değişen karakterde olduğundan, azalma veya artma eğiliminin araştırılmasında özel yöntemlerin kullanılması gerekir (Helsel ve Hirsch, 1992).

$\mathrm{Bu}$ çalışmada, Karadeniz Bölgesinde bulunan 6 adet istasyona ait 1960-2016 yılları arasındaki aylık toplam yağış $(\mathrm{mm})$ verileri, ortalama rüzgâr hızı $(\mathrm{m} / \mathrm{s})$, buharlaşma $(\mathrm{mm})$ ve ortalama sicaklık verileri ( ${ }^{\mathrm{C}}$ ) kullanılarak trend analizleri iki farklı yöntemle karşılaştırmalı olarak incelenmiştir. Analizlerde, M-MK ve LT yöntemler aylık, yıllık bazda ve $\% 95$ güven aralığında incelenmiş ve trendler Coğrafi Bilgi Sistemleri teknolojileri yardımıyla haritalandırılmıştır. Çalışmada kullanılan M-MK yöntemi parametrik olmayan testlerdendir. LT ise parametrik bir testtir (Gümüş, 2006). Trend analizlerinin gerçekleştirilmesinde Microsoft Office Excel programı ve MATLAB kullanılmış, haritalar ArcGIS yazılımı kullanılarak oluşturulmuştur. LT ve M-MK yöntemlerine ait yıllık sonuçlar Tablo 4'de, aylık sonuçlar ise Tablo 2 ve 3'de yer almaktadır. 
Tablo 2. Yıllık Trend Sonuçları

\begin{tabular}{|c|c|c|c|}
\hline İstasyon & Parametre & LT & M-MK \\
\hline \multirow{2}{*}{ Giresun } & Sicaklik & 3.74 & 3.33 \\
\hline & YağıŞ & 3.49 & 3.57 \\
\hline \multirow{2}{*}{ Tabzon } & Sicaklik & 1.05 & 0.96 \\
\hline & Yağıs & 5.41 & 4.93 \\
\hline \multirow{2}{*}{ Rize } & Sicaklik & 4.83 & 5.37 \\
\hline & Yağış & 2.51 & 2.11 \\
\hline \multirow{2}{*}{ Artvin } & Sicaklik & 1.44 & 1.74 \\
\hline & $Y a \breve{g}_{l S ̧}$ & 1.98 & 2.21 \\
\hline \multirow{2}{*}{ Gümüşhane } & Sicaklik & 2.94 & 2.25 \\
\hline & Yağış & 2.08 & 2.07 \\
\hline \multirow{2}{*}{ Bayburt } & Sicaklik & 2.53 & 2.83 \\
\hline & Yăglş & 2.51 & 2.66 \\
\hline
\end{tabular}

Tablo 2 incelendiğinde güven aralığının \%95'lik kısmında istatistiksel olarak anlamlı eğilim gösteren sonuçlar koyu/bold olarak belirtilmiştir. Giresun istasyonuna ait sıcaklık ve yağışlar incelendiğinde, her iki değişkeninde hem LT hem de M-MK yöntemlerine göre artan yönde eğilim gösterdiği görülmüştür. Trabzon istasyonu incelendiğinde, her iki yönteme göre de sıcaklıklar artan yönde eğilim gösterse de bu eğilim istatistiksel olarak anlamlı değildir. Trabzon istasyonunda yağışlar ise artan yönde bir eğilim göstermektedir. Rize istasyonunda sonuçlar Giresun, Gümüşhane ve Bayburt istasyonlarına benzer şekilde her iki yöntemde de iki parametrede artan yönde eğilim göstermektedir. Artvin istasyonunda ise sadece yağış değerleri MMK yöntemine göre anlamlı bir artış eğilimi göstermektedir. Sonuç olarak, LT ve M-MK yöntemi benzer sonuçlar vererek (Artvin istasyonu yağışları hariç) bölgede hem yağış hem de sıcaklık değerlerinin artan yönde eğilim gösterdiği tespit edilmiştir.

Tablo 3. Yıllık Trend Sonuçları

\begin{tabular}{cccc}
\hline İstasyon & Parametre & LT & M-MK \\
\hline \multirow{2}{*}{ Giresun } & Rüzgar & 0.61 & 0.13 \\
& Buharlaşma & $*$ & $*$ \\
Tabzon & Rüzgar & $\mathbf{5 . 3 8}$ & $\mathbf{6 . 6 2}$ \\
& Buharlaşma & 2.46 & 1.87 \\
Rize & Rüzgar & $\mathbf{- 8 . 8 2}$ & $\mathbf{- 5 . 6 0}$ \\
& Buharlaşma & $*$ & $*$ \\
Artvin & Rüzgar & -0.69 & -0.84 \\
& Buharlaşma & $*$ & $*$ \\
Gümüşhane & Rüzgar & 0.13 & 0.38 \\
& Buharlaşma & 2.06 & $\mathbf{1 . 9 7}$ \\
Bayburt & Rüzgar & $\mathbf{- 8 . 0 6}$ & $\mathbf{- 3 . 6 3}$ \\
& Buharlaşma & -1.52 & -1.10 \\
\hline
\end{tabular}

*: veri sayısı trend testlerini uygulamak için gereken veri sayısından az olduğu $(<30)$ için test gerçekleştirilmemiştir.

Tablo 3 incelendiğinde güven aralığının \%95'lik kısmında istatistiksel olarak anlamlı eğilim gösteren sonuçlar koyu/bold olarak belirtilmiştir. Trabzon istasyonu incelendiğinde rüzgâr verileri için her iki yöntemde de artan yönde istatistiksel olarak anlamlı trend varlığı bulunduğu sonucuna ulaşılmıştır. Rize istasyonuna ait rüzgâr verileri incelendiğinde ise her iki yöntemde negatif yönde anlamlı trend varlığı bulunduğu sonucu elde edilmiştir. Gümüşhane istasyonunda buharlaşma verileri incelendiğinde Modifiye Mann-Kendall yöntemine göre istatistiksel olarak anlamlı pozitif yönde trend söz konusu olduğu tespit edilmiştir. Bayburt istasyonu incelendiğinde ise Rize ve Trabzon istasyonlarında olduğu gibi iki test rüzgâr verileri için benzer sonuçlar vermiş ve negatif yönde anlamlı trend varlığı gözlenmiş̧ir. 
Tablo 4. Sicaklıklara ait trend analizi sonuçları

\begin{tabular}{|c|c|c|c|c|c|c|c|c|c|c|c|c|c|}
\hline \multirow[b]{2}{*}{ İstasyon } & \multicolumn{12}{|c|}{ Aylar } & \multirow[b]{2}{*}{ Yöntem } \\
\hline & $O c a$ & $S ̧ u b$ & Mar & Nis & May & $\mathrm{Haz}$ & Tem & $A \breve{g u}$ & $E y l$ & $E k i$ & Kas & Ara & \\
\hline \multirow{2}{*}{ Giresun } & 1.24 & 0.67 & 1.31 & 0.91 & 1.89 & 3.74 & 5.12 & 7.12 & 4.36 & 2.31 & -0.32 & -0.58 & $L T$ \\
\hline & 1.58 & 1.37 & 1.52 & 1.15 & 2.30 & 5.37 & 6.44 & 5.66 & 3.83 & 2.11 & -0.23 & -0.96 & $M-M K$ \\
\hline \multirow{2}{*}{ Trabzon } & 0.13 & ${ }^{-}$ & 0.43 & 1.27 & 1.16 & 1.90 & 3.44 & 4.32 & 2.06 & 0.27 & -2.39 & -2.21 & $L T$ \\
\hline & -0.06 & 0.08 & 0.47 & 1.92 & 1.38 & 3.04 & 3.10 & 3.70 & 1.73 & 0.33 & -4.69 & -5.37 & $M-M K$ \\
\hline \multirow{2}{*}{ Rize } & 0.67 & 0.71 & 1.52 & 1.30 & 3.33 & 5.25 & 6.16 & 7.68 & 5.54 & 2.96 & -0.45 & -0.74 & $L T$ \\
\hline & 0.78 & 0.82 & 1.51 & 1.65 & 2.88 & 5.12 & 7.11 & 5.87 & 7.43 & 2.84 & -0.32 & -1.97 & $M-M K$ \\
\hline \multirow{2}{*}{ Artvin } & 0.38 & 0.51 & 0.14 & -0.14 & -0.01 & 1.96 & 2.86 & 4.10 & 2.16 & 0.96 & -1.15 & -0.57 & $L T$ \\
\hline & 0.46 & 0.44 & 0.43 & -0.34 & -0.40 & 1.79 & 2.57 & 3.53 & 1.64 & 0.97 & -0.69 & -0.82 & $M-M K$ \\
\hline \multirow{2}{*}{ Gümüşhane } & 1.36 & 1.38 & 0.75 & 0.93 & 0.62 & 2.55 & 2.59 & 3.29 & 2.69 & 2.63 & 0.01 & -0.02 & $L T$ \\
\hline & 1.84 & 1.45 & 0.85 & 0.87 & -0.12 & 2.14 & 1.86 & 2.52 & 0.98 & 2.16 & 0.09 & -0.29 & $M-M K$ \\
\hline \multirow{2}{*}{ Bayburt } & 1.28 & 1.35 & 1.99 & 1.37 & 0.82 & 2.84 & 1.87 & 3.80 & 1.39 & 1.26 & -0.42 & -0.64 & $L T$ \\
\hline & 1.34 & 1.32 & 11.75 & 2.39 & 0.93 & 3.35 & 1.97 & 3.46 & 0.93 & 1.65 & -0.39 & -0.60 & $M-M K$ \\
\hline
\end{tabular}

Tablo 4'te güven aralığının \%95'lik kısmında istatistiksel olarak anlamlı eğilim gösteren sıcaklık sonuçları koyu/bold olarak belirtilmiştir. Aylık sonuçlar incelendiğinde ocak ve şubat aylarında herhangi bir trend gözlemlenmezken ağustos ayında tüm istasyonlarda artan yönde eğilim görülmektedir. Bölgede artan eğilimler özellikle Mayıs - Ekim aylarında görülmektedir ve artan yöndedir. Ayrıca Kasım-Aralık aylarında genellikle azalan yönde eğilimler görülse de Trabzon (LT ve M-MK) ve Rize (M-MK) istasyonlarında bu azalışlar anlamlıdır. Her iki yönteme göre de toplamda 12x6=72 analiz bulunmaktadır ve bu analizlerden sadece 10 tanesi uyumsuzdur. Yani 10 istasyonda yöntemin biri anlamlı eğilim gösterirken diğeri anlamlı olmayan eğilim göstermiştir. Bu da yöntemleri \%86.1 oranında benzer sonuçlar verdiğini göstermektedir \% $86.1(((72-10) \times 100) / 72)$.

Tablo 5. Yă̆lşlara ait trend analizi sonuçları

\begin{tabular}{|c|c|c|c|c|c|c|c|c|c|c|c|c|c|}
\hline \multirow[b]{2}{*}{ İstasyon } & \multicolumn{12}{|c|}{ Aylar } & \multirow[b]{2}{*}{ Yöntem } \\
\hline & $O c a$ & Şub & Mar & Nis & May & $\mathrm{Haz}$ & Tem & $A \breve{g} u$ & Eyl & $E k i$ & Kas & Ara & \\
\hline \multirow{2}{*}{ Giresun } & 0.29 & -0.65 & 1.20 & -1.01 & 1.11 & 1.60 & 0.99 & -0.93 & 1.69 & 2.15 & 1.56 & 0.04 & $L T$ \\
\hline & 0.32 & 0.01 & 1.07 & -1.01 & 0.94 & 1.40 & 0.30 & -0.72 & 1.03 & 2.82 & 1.51 & 0.00 & $M-M K$ \\
\hline \multirow{2}{*}{ Trabzon } & 1.51 & 0.50 & 1.70 & 0.72 & 0.90 & 0.13 & 0.30 & 1.95 & 1.15 & 2.16 & 0.96 & 1.08 & $L T$ \\
\hline & 1.34 & 0.97 & 1.71 & 0.77 & 0.80 & -0.2 & 0.32 & 1.16 & 0.85 & 2.68 & 1.56 & 0.77 & $M-M K$ \\
\hline \multirow{2}{*}{ Rize } & -0.12 & -0.47 & 0.17 & -1.10 & -0.45 & 1.87 & 1.55 & 0.01 & 1.84 & 2.64 & 0.33 & 0.19 & $L T$ \\
\hline & -0.71 & -0.35 & 0.56 & -0.88 & -0.44 & 1.50 & 1.18 & -0.06 & 2.74 & 2.23 & 0.30 & 0.82 & $M-M K$ \\
\hline \multirow{2}{*}{ Artvin } & 0.53 & 0.18 & 1.76 & -0.06 & 0.48 & 0.51 & 1.47 & 1.37 & 1.59 & 1.04 & 0.88 & -0.83 & $L T$ \\
\hline & 0.66 & -0.17 & 1.58 & -0.49 & 0.72 & 0.30 & 1.39 & 1.54 & 0.36 & 1.63 & 0.35 & -0.62 & $M-M K$ \\
\hline \multirow{2}{*}{ Gümüşhane } & 0.91 & 1.36 & 1.10 & 1.16 & -0.39 & 0.35 & 1.38 & 0.54 & 2.42 & 1.52 & 0.56 & -2.09 & $L T$ \\
\hline & 1.53 & 1.22 & 1.37 & 1.09 & -0.24 & 0.14 & 3.00 & 1.20 & 3.75 & 1.32 & 0.00 & -1.94 & $M-M K$ \\
\hline \multirow{2}{*}{ Bayburt } & 1.81 & 1.81 & 1.71 & 1.74 & 0.98 & -1.7 & 1.44 & 0.69 & 0.82 & 1.96 & -0.43 & -0.39 & $L T$ \\
\hline & 1.54 & 2.40 & 1.50 & 1.91 & 2.46 & -1.6 & 1.71 & 1.10 & 0.46 & 2.81 & -0.5 & 1.54 & $M-M K$ \\
\hline
\end{tabular}

Tablo 5'te güven aralığının \%95'lik kısmında istatistiksel olarak anlamlı eğilim gösteren yağış sonuçları koyu/bold olarak belirtilmiştir. Toplam yağışlara ait aylık sonuçlar incelendiğinde, eğilimler genellikle Ekim aylarında anlamlı ve artan yöndedir. Azalan 
yönde eğilimler ise sadece Gümüşhane (LT) istasyonunda görülmektedir. Yöntemlere ait sonuçlar \% 91.6 (((72-6)x100)/72) oranında benzerdir. Toplamda $12 \times 6=72$ analiz bulunmaktadır ve bu analizlerden sadece 6 tanesi uyumsuzdur. Yani 6 istasyonda (Rize-Eylül, Gümüşhane-Aralık-Temmuz, Bayburt-Şubat-Mayıs-Ekim) yöntemin biri anlamlı eğilim gösterirken diğeri anlamlı olmayan eğilim göstermiştir.

Tablo 6. Rüzgâr ait trend analizi sonuçları

\begin{tabular}{|c|c|c|c|c|c|c|c|c|c|c|c|c|c|}
\hline \multirow{2}{*}{ İstasyon } & \multicolumn{12}{|c|}{ Aylar } & \multirow[b]{2}{*}{ Yöntem } \\
\hline & Oca & $S ̧ u b$ & Mar & Nis & May & $H a z$ & $\mathrm{Tem}$ & $A \breve{g} u$ & Eyl & $E k i$ & Kas & Ara & \\
\hline \multirow{2}{*}{ Giresun } & 0.15 & 0.71 & 2.26 & 1.31 & 1.07 & 0.86 & 1.19 & -0.16 & 0.22 & -0.74 & -0.30 & 0.01 & $L T$ \\
\hline & 0.32 & 0.39 & 1.97 & 0.59 & 1.39 & 0.52 & 0.97 & -0.20 & -0.36 & -0.92 & -0.20 & -0.18 & $M-M K$ \\
\hline \multirow{2}{*}{ Trabzon } & 4.01 & 2.17 & 2.88 & 3.52 & 3.22 & 4.14 & 5.94 & 5.10 & 4.52 & 3.95 & 3.94 & 3.03 & $L T$ \\
\hline & 3.48 & 1.48 & 2.70 & 3.53 & 3.90 & 3.42 & 16.16 & 4.48 & 3.91 & 3.64 & 4.57 & 2.59 & $M-M K$ \\
\hline \multirow{2}{*}{ Rize } & -5.57 & -5.47 & -2.92 & -3.29 & -3.72 & -7.45 & -8.03 & -6.35 & -8.71 & -7.80 & -5.77 & -10.35 & $L T$ \\
\hline & -5.01 & -4.07 & -2.06 & -3.49 & -2.42 & -4.68 & -5.26 & -5.23 & -5.73 & -10.67 & -3.42 & -5.86 & $M-M K$ \\
\hline \multirow{2}{*}{ Artvir } & -1.72 & -0.61 & -0.73 & 0.82 & -1.28 & 1.33 & 0.39 & 1.06 & 0.24 & -1.57 & -0.41 & -1.54 & $L T$ \\
\hline & -1.22 & -0.80 & -2.04 & 0.12 & -1.02 & 1.36 & 0.66 & 1.36 & 0.34 & -1.53 & -0.05 & -1.12 & $M-M K$ \\
\hline \multirow{2}{*}{ Gümüşhan } & -0.60 & -2.03 & -0.11 & 1.28 & 0.54 & 0.44 & 0.83 & 1.29 & 1.49 & 0.42 & -1.32 & -2.60 & $L T$ \\
\hline & 0.07 & -0.99 & 1.15 & 2.04 & 1.07 & 1.07 & 0.91 & 0.63 & 0.69 & 0.91 & -0.59 & -1.31 & $M-M K$ \\
\hline \multirow{2}{*}{ Bayburt } & -6.06 & -5.53 & -5.19 & -5.62 & -5.75 & -6.30 & -7.65 & -10.54 & -8.51 & -6.12 & -5.82 & -6.60 & $L T$ \\
\hline & -5.49 & -5.11 & -3.98 & -3.15 & -3.88 & -3.72 & -4.59 & -9.52 & -5.18 & -4.84 & -3.90 & -3.98 & $M-M K$ \\
\hline
\end{tabular}

Tablo 6'da güven aralığının \%95'lik kısmında istatistiksel olarak anlamlı eğim gösteren rüzgâr sonuçları koyu/bold olarak belirtilmiştir. Rüzgarlara ait sonuçlar aylık olarak incelendiğinde, eğilimler genellikle Trabzon, Rize ve Bayburt istasyonlarında yoğun olarak trend varlığı saptanmış ve yöntemlere ait sonuçlar \%95.8 (((72-3)x100)/72) oranında benzerdir. Toplamda 72 (12x6) analiz bulunmakta ve bu analizlerden sadece 3 tanesi uyumsuzdur. Yani 6 istasyonda (Giresun-Mart, Artvin-Mart, Gümüşhane-Nisan) yöntemlerden biri anlamlı eğilim gösterirken diğeri anlamlı olmayan eğilim göstermiştir.

Tablo 7. Buharlaşmalara ait trend analizi sonuçları

\begin{tabular}{cccccccc}
\hline \multirow{2}{*}{ İstasyon } & \multicolumn{7}{c}{ Aylar } \\
& May & Haz & Tem & Ăgu & $E y l$ & Eki & Yöntem \\
\hline \multirow{2}{*}{ Trabzon } & 1.74 & 0.93 & 2.25 & $\mathbf{3 . 1 4}$ & $\mathbf{3 . 4 7}$ & -0.98 & $L T$ \\
& 1.34 & 1.79 & $\mathbf{2 . 3 6}$ & $\mathbf{4 . 4 2}$ & $\mathbf{4 . 9 4}$ & -0.44 & $M-M K$ \\
\multirow{2}{*}{ Gümüşhane } & 1.23 & 1.13 & 2.28 & $\mathbf{3 . 1 2}$ & 1.82 & 0.51 & $L T$ \\
& 1.22 & 1.39 & $\mathbf{2 . 3 9}$ & $\mathbf{2 . 7 0}$ & 1.75 & 0.54 & $M-M K$ \\
\multirow{2}{*}{ Bayburt } & -1.30 & -1.26 & -0.55 & -0.26 & -0.25 & $\mathbf{- 2 . 9 4}$ & $L T$ \\
& -1.11 & -0.86 & -0.45 & -0.31 & -1.30 & $\mathbf{- 2 . 8 0}$ & $M-M K$ \\
\hline
\end{tabular}

Tablo 7'de Giresun, Rize, Artvin, istasyonlarında buharlaşma verilerine ait veri sayısı 30'dan küçük olduğu için analizler gerçekleştirilmemiştir. Güven aralığının \%95'lik kısmında istatistiksel olarak anlamlı eğim gösteren buharlaşma sonuçları koyu/bold olarak belirtilmiştir. Buharlaşmalara ait sonuçlar aylık olarak incelendiğinde, eğilimler genellikle Temmuz, Ağustos, Eylül ve Ekim aylarında rastlanmıştır. Yöntemlere ait sonuçlar \%97.22 (((72-2)x100)/72) oranında benzerdir. Toplamda 72 (12x6) analiz bulunmakta ve bu analizlerden sadece 2 tanesi uyumsuzdur. Yani 6 istasyonda (Trabzon-Temmuz, Gümüşhane-Temmuz) yöntemlerden biri anlamlı eğilim gösterirken diğeri anlamlı olmayan eğilim göstermiştir.

Elde edilen yıllık sonuçlar ArcGIS ortamına aktarılarak sıcaklık verileri için Şekil 2 ve Şekil 3'te, yağış verileri için Şekil 4 ve Şekil 5'te, rüzgâr veriler için Şekil 6 ve Şekil 7'de, buharlaşma verileri için ise Şekil 8 ve Şekil 9'da trend haritaları oluşturulmuştur. 


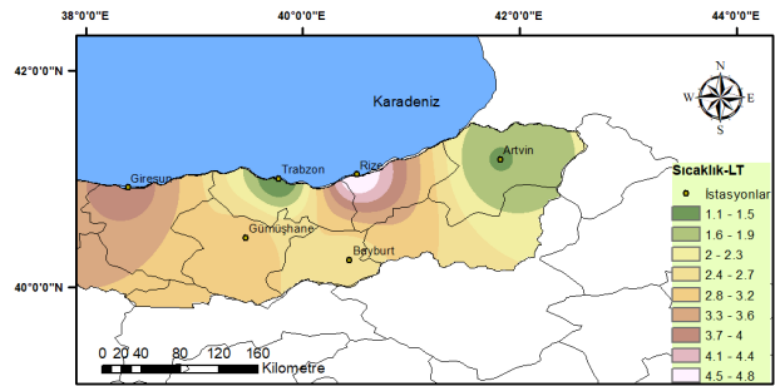

Şekil 2. Lineer trend yöntemine ait sıcaklık haritası

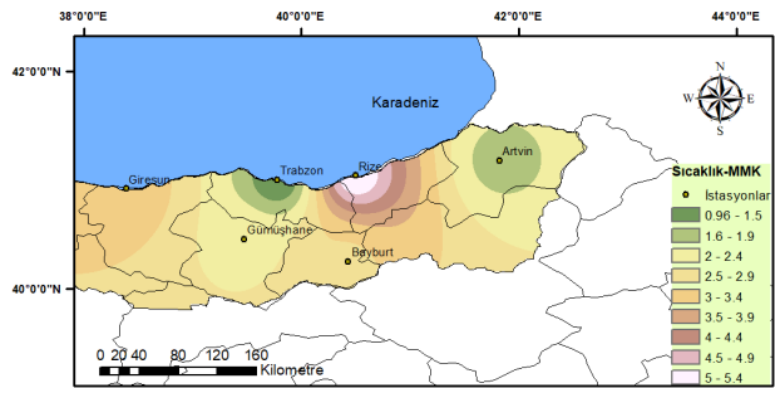

Şekil 3. Modifiye Mann-Kendall yöntemine ait sıcaklık haritası



Şekil 4. Lineer trend yöntemine ait yağış haritası

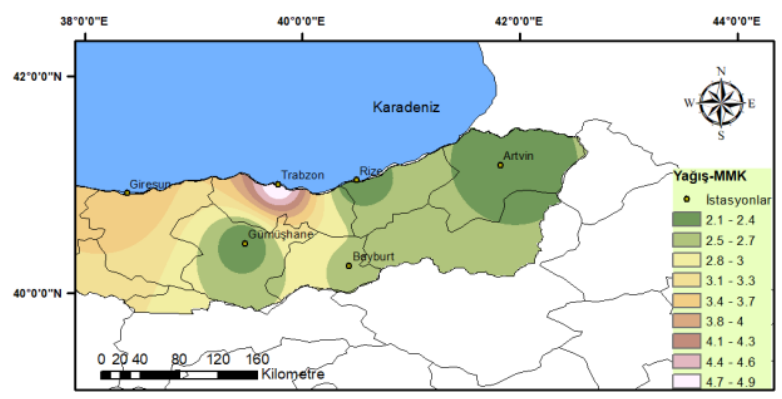

Şekil 5. Modifiye Mann-Kendall yöntemine ait yağış haritası



Şekil 6. Lineer trend yöntemine ait rüzgâr haritası

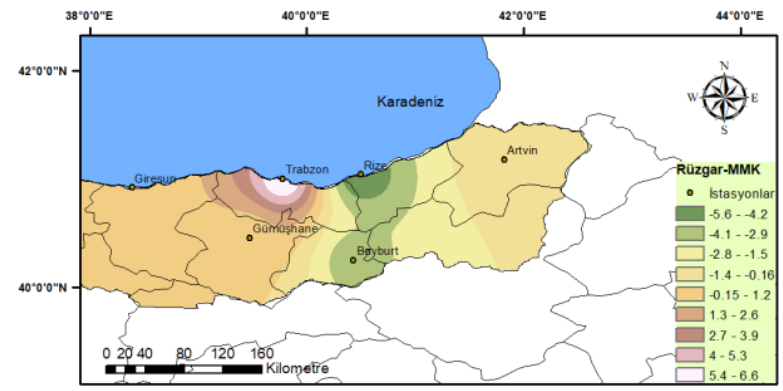

Şekil 7. Modifiye Mann-Kendall yöntemine ait rüzgar haritası

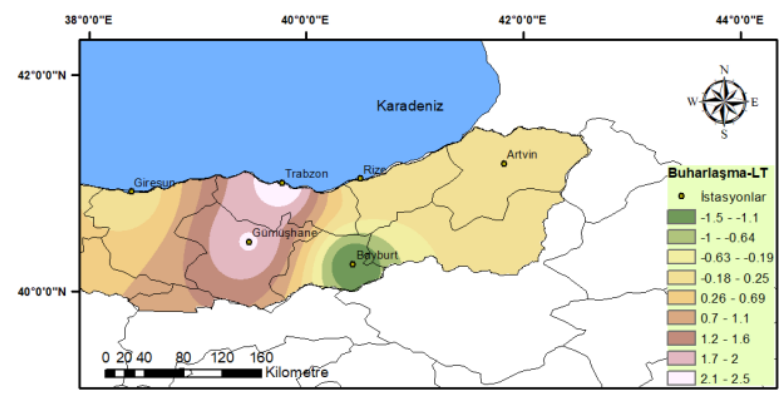

Şekil 8. Lineer trend yöntemine ait buharlaşma haritası

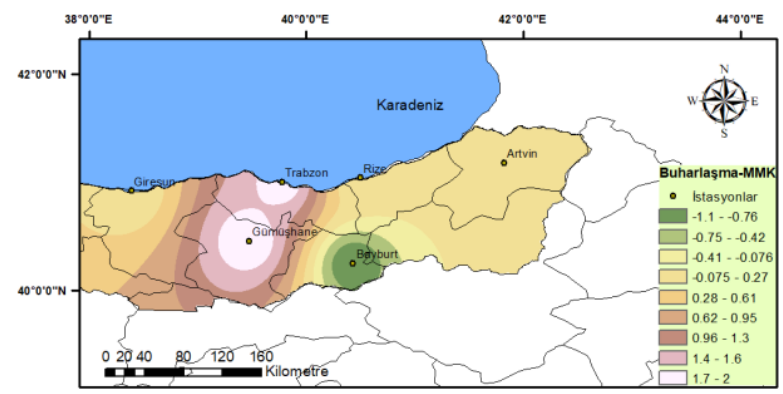

Şekil 9. Modifiye Mann-Kendall yöntemine ait buharlaşma haritası

\section{Sonuçlar}

$\mathrm{Bu}$ çalışmada, Karadeniz Bölgesi'nde yer alan Giresun, Trabzon, Rize, Artvin, Gümüşhane ve Bayburt meteoroloji gözlem istasyonlarına ait 1960-2016 yılları arasındaki aylık toplam yağış verileri $(\mathrm{mm})$, ortalama rüzgâr hızı $(\mathrm{m} / \mathrm{s})$, buharlaşma $(\mathrm{mm})$ ve ortalama sıcaklık verileri (C) üzerinde trend analizleri gerçekleştirilmiştir. Analizlerde LT ve M-MK yöntemleri güven aralığının \%95'lik kısmında test edilmiştir. Sonuçlar aylık ölçeklerde tablo ve yıllık ölçeklerde hem tablo hem de Coğrafi Bilgi Sistemi teknikleriyle hazırlanmış haritalar ile görselleştirilmiştir. Sonuçlar incelendiğinde ise;

- $\quad$ LT ve M-MK yöntemleri \%86.1-\%97.22 oranında benzer sonuçlar vermiştir.

- Doğu Karadeniz Bölgesi'nde yıllık sonuçlar hem yağış değerleri hem de sıcaklık değerleri için artan yönde eğilim gösterdiği tespit edilmiştir.

- Aylık sonuçlar incelendiğinde ise hem yağış değerleri hem de sicaklık değerleri genellikle artan yönde eğilim göstermektedir.

- Şekil 2-9'da bulunan haritalar incelendiğinde LT ve MMK yönteminden elde edilen sonuçların benzer olduğu bir kez 
daha görülmekte ve sıcaklık verileri için hazırlanmış olan Şekil 2 ve Şekil 3 incelendiğinde maksimum trend değerinin Rize'de, minimum trend değerinin ise Trabzon'da bulunduğu, yağış verileri için hazırlanmış olan Şekil 4 ve Şekil 5 incelendiğinde maksimum trend değerinin Trabzon'da bulunduğu, minimum trend değerinin ise Artvin'de bulunduğu, rüzgâr verileri için hazırlanmış olan Şekil 6 ve Şekil 7 incelendiğinde maksimum trend değerinin Trabzon'da bulunduğu, minimum trend değerinin ise Rize'de bulunduğu, buharlaşma verileri için hazırlanmış olan Şekil 8 ve Şekil 9 incelendiğinde maksimum trend varlı̆̆ Trabzon'da, minimum trend ise Bayburt'ta gözlemlenmiştir.

\section{Kaynaklar}

Çeribaşı, G. (2019). Şen Yöntemi ve Trend Yöntemleri Kullanılarak Doğu Karadeniz Havzasının Yağış Verilerinin Analiz Edilmesi. Iğdır Üniversitesi Fen Bilimleri Enstitüsü Dergisi, 9(1), 254-264. DOI: 10.21597/jist.439569

Çeribaşı, G. ve Doğan, E. (2015) Karadeniz ve Sakarya Havzalarında Yıllık Ortalama Yağışların Trend Analizi. SDU International Technologic Science. 7(1), 1-7.

Demir, V. (2018). Karadeniz Bölgesi Yağışlarının Trend Analizi. Yüksek Lisans Tezi. Ondokuzmayıs Üniversitesi Fen Bilimleri Enstitüsü Harita Mühendisliği Anabilim Dalı, Samsun. 148 p.

Gümüş, V. (2006). Fırat Havzası Akımlarının Trend Analizi ile Değerlendirilmesi. Yüksek Lisans Tezi, Harran Üniversitesi Fen Bilimleri Enstitüsü İnşaat Mühendisliği Anabilim Dalı, Şanlıurfa. 75 p.

Helsel, D. R. and Hirsch, R. M. (1992). Statistical Methods in Water Resources. Techniques of Water-Resources Investigations of the United States. Geological Survey, Amsterdam. $546 \mathrm{p}$.

Hamed, K. H. and Rao, A. R. (1998). A Modified MannKendall Trend Test for Autocorrelated Data. 204:182-96.

Kendall, M. G. (1975). Rank Correlation Methods. Chtirles Griffin, London. 68 p.

Karabulut, M. And Cosun, F. (2009). Kahramanmaraş İlinde Yağışların Trend Analizi. Coğrafi Bilimler Dergisi 7(1), 65-83.

Mann, H. B. (1945). Non-Parametric Test Against Trend. Econometrika, 13:3,245-259.

Nemli, M. Ö. (2017). Doğu Karadeniz Bölgesi'nde Yıllık Maksimum Yağış̧ların Trend Analizi. Yüksek Lisans Tezi Karadeniz Teknik Üniversitesi Fen Bilimleri Enstitüsü İnşaat Mühendisliği Anabilim Dalı, Trabzon. 106 p.

Özkoca, T. (2015). Orta Karadeniz Bölgesi Kıyı İllerinin Hidrometeorolojik Parametrelerinin Trend Analizi. Yüksek Lisans Tezi, Ondokuz Mayıs Üniversitesi Fen Bilimleri Enstitüsü İnşaat Mühendisliği Anabilim Dalı, Samsun. $77 \mathrm{p}$.

Partal, T. (2003). Türkiye Yağış Verilerinin Trend Analizi. Yüksek Lisans Tezi İstanbul Teknik Üniversitesi Fen Bilimleri Enstitüsü, İstanbul. 101 p.

Yu, Yun-Sheng, Zou, S., and Whittemore, D. (1993). NonParametric Trend Analysis of Water Quality Data of Rivers in Kansas. Journal of Hydrology 150(1), 61-80.

Yılmaz, A. (2018). Batı Karadeniz Bölümünde Sicaklık ve Yağış Verilerinin Trend Analizi. Yüksek Lisans Tezi, Karabük Üniversitesi Sosyal Bilimler Enstitüsü Coğrafya Anabilim Dalı, Karabük. 361 p. 